\title{
Esophagobronchial Fistula in a Patient with Squamous Cell Carcinoma of the Lung: A Case Report
}

\author{
Taichi Ozeki $^{a}$ Michiko Asano $^{b} \quad$ Nobukazu Fujimoto $^{c}$ Jun Nishimura ${ }^{a}$ \\ Kenji Takada ${ }^{a}$ Yosuke Miyamoto $^{b}$ Yasuko Fuchimoto ${ }^{b}$ Sae Wada ${ }^{b}$ \\ Shinji Ozaki ${ }^{b} \quad$ Takumi Kishimoto $^{a}$ \\ ${ }^{a}$ Department of Medicine, Okayama Rosai Hospital, Okayama, Japan; ${ }^{b}$ Department of \\ Pulmonary Medicine, Okayama Rosai Hospital, Okayama, Japan; 'Department of Medical \\ Oncology, Okayama Rosai Hospital, Okayama, Japan
}

\section{Keywords}

Fistula - Squamous cell carcinoma · Chemoradiotherapy · Cisplatin · Docetaxel · Lung tumor

\section{Abstract}

A 73-year-old man was referred to our hospital after a 2-week history of bloody sputum and cough. Computed tomography (CT) images of the chest showed a mass grouped with mediastinal lymph nodes, and bronchoscopy showed a projecting mass in the right main bronchus. After a transbronchial biopsy, the patient was diagnosed with squamous cell carcinoma (T4N2M0 stage IIIB). The patient was treated with systemic chemotherapy, consisting of cisplatin $\left(40 \mathrm{mg} / \mathrm{m}^{2}\right.$, days 1 and 8$)$ and docetaxel $\left(30 \mathrm{mg} / \mathrm{m}^{2}\right.$, days 1 and 8$)$, and concurrent thoracic irradiation at a daily dose of $2 \mathrm{~Gy}$. On day 35 of treatment, the patient complained of a sore throat and cough. A CT of the chest showed punctate low-attenuation foci between the esophagus and bronchus. Gastrointestinal endoscopy and bronchoscopy demonstrated a fistula in the middle intrathoracic esophagus and the left main bronchus. The patient's symptoms gradually improved, and the fistula was closed after the suspension of chemoradiotherapy. Radiotherapy was resumed and completed on day 82 . However, on day 108 , he developed a fever and cough, and a tumor with fistula was revealed in the right main bronchus. He had an esophageal stent inserted, but he later died of sudden hemoptysis. 


\section{Case Reports in Oncology}

\begin{tabular}{l|l}
\hline Case Rep Oncol 2017;10:553-557 \\
\hline DOI: 10.1159/000477659 & $\begin{array}{l}\text { C 2017 The Author(s). Published by S. Karger AG, Basel } \\
\text { www.karger.com/cro }\end{array}$ \\
\hline
\end{tabular}

Ozeki et al.: Esophagobronchial Fistula in a Patient with Squamous Cell Carcinoma of the Lung: A Case Report

\section{Introduction}

An esophagobronchial fistula represents a connection between the esophagus and the bronchus, resulting from direct neoplastic infiltration and necrosis between the esophagus, bronchi, and mediastinum [1]. A fistula could also be induced by necrosis or cytoreduction of the tumor, though there is no clear evidence that treatment modalities such as chemotherapy or radiotherapy increase the incidence of fistula formation [2]. We report on a patient with squamous cell carcinoma of the lung who developed an esophagobronchial fistula twice in his clinical course. The first one developed during chemoradiotherapy, and the second one was thought to be due to extension of the tumor.

\section{Case Report}

A 72-year-old Japanese man was referred to our hospital after 2 weeks of bloody sputum and cough. He had a history of hypertension but was not treated with medication. He had smoked between the ages of 20 and 72 years, and had been exposed to asbestos at shipyards for 15 years. Physical examination revealed a slight wheeze in the bilateral lungs, and no superficial lymph nodes were palpated. A blood test revealed elevated white blood cells, C-reactive protein, and serum calcium levels. Tumor markers were slightly elevated in carcinoembryonic antigen $(13.4 \mathrm{ng} / \mathrm{mL})$ and cytokeratin 19 fragment $(12.9 \mathrm{ng} / \mathrm{mL})$. Computed tomography (CT) of the chest showed a $60-\mathrm{mm}$ mass grouped with mediastinal lymph nodes, which invaded the right main bronchus (Fig 1a, b). After a transbronchial biopsy of the mass, the diagnosis of squamous cell carcinoma was made. The staging workup, including magnetic resonance imaging of the brain and whole-body fluorine-18 2-fluoro-2-deoxyd-glucose positron emission tomography, revealed his disease as cT4N2M0, stage IIIB.

The patient was treated with systemic chemotherapy, consisting of cisplatin $\left(40 \mathrm{mg} / \mathrm{m}^{2}\right.$, days 1 and 8 ) and docetaxel ( $30 \mathrm{mg} / \mathrm{m}^{2}$, days 1 and 8$)$, and concurrent thoracic irradiation at a daily dose of $2 \mathrm{~Gy}$. On day 35 of treatment, he complained of a sore throat and cough, and a CT of the chest showed punctate low-attenuation foci between the esophagus and bronchus (Fig. 1c). Gastrointestinal endoscopy and bronchoscopy demonstrated a fistula in the middle intrathoracic esophagus and the left main bronchus, respectively (Fig. 2a, b). After the suspension of chemoradiotherapy and abstaining from eating, his symptoms gradually improved and the fistula was closed on day 52 (Fig. 2c). Radiotherapy at 2 Gy was resumed every other day and 60 Gy was completed on day 82 . The fistula remained closed and the patient was discharged after the second course of chemotherapy.

However, he was referred to our hospital for a sore throat and fever again on day 108. A CT of the chest showed a clear connection between the esophagus and the right main bronchus (Fig. 3a), and there was ground glass opacity spread in the right lower lung. Bronchoscopy demonstrated a mass with the fistula in the right main bronchus (Fig. 3b). Pathological analyses of the mass showed poorly differentiated squamous cell carcinoma. Based on these findings, the patient was diagnosed with a relapse of the cancer. He had an esophageal stent inserted; however, he died of sudden hemoptysis on day 146. An autopsy was not allowed. 
Ozeki et al.: Esophagobronchial Fistula in a Patient with Squamous Cell Carcinoma of the Lung: A Case Report

\section{Discussion}

The development of an esophagobronchial fistula is a devastating and life-threating complication. The incidence of fistula in lung cancer is rare compared with that in esophageal cancer ( 0.16 vs. $4.9 \%$ ). A fistula may occur in lung cancer when the tumor makes contact with the esophagus [2]. In the current case, the tumor was located in the mediastinal space and close to the middle intrathoracic esophagus. The first fistula was considered the result of tumor necrosis and damage to the mucous membrane induced by chemoradiotherapy, because the fistula developed in the left main bronchus and the initial tumor in the right main bronchus disappeared at that time. This speculation was also supported by the finding that the fistula improved after 3 weeks' interruption of chemoradiotherapy. On the other hand, the second fistula was considered the result of tumor progression, because the fistula was associated with a tumor that had the same histology as the initial tumor. To our knowledge, this is the first report of an esophagobronchial fistula developing twice in 1 patient by different mechanisms.

An esophagobronchial fistula is a serious complication and the survival time is around 8 months [3]. Direct surgical closure, chemotherapy, and radiotherapy [4] may be used to close the fistula. However, the utility of these treatments was not established, and stent insertion is currently recommended in such situations for symptomatic relief [5]. An esophageal stent was inserted in the current case; however, long-term symptomatic relief was not obtained due to massive hemoptysis.

Chemoradiotherapy is a standard treatment option for locally advanced lung cancer [6], even in cases where the tumor is located close to or invades the esophagus. In such cases, physicians should be extremely cautious about the development of esophagobronchial fistula during and after treatment. In addition to the CT scanning, gastrointestinal endoscopy, before and during treatment, might be considered for early detection of a fistula. In conclusion, we reported a case of squamous cell carcinoma of the lung in a patient who twice developed an esophagobronchial fistula that was caused by different mechanisms.

\section{Acknowledgement}

This study was supported by The Research, Development, and Dissemination of Projects Related to Nine Fields of Occupational Injuries and Illnesses of the Japan Labour Health and Welfare Organization and by grants-in-aid from the Ministry of Health, Labor and Welfare, Japan.

\section{Statement of Ethics}

The authors have no ethical conflicts to disclose.

\section{Disclosure Statement}

The authors declare that they have no conflict of interest. 


\section{Case Reports in Oncology}

\begin{tabular}{l|l}
\hline Case Rep Oncol 2017;10:553-557 \\
\hline DOI: 10.1159/000477659 & $\begin{array}{l}\text { @ 2017 The Author(s). Published by S. Karger AG, Basel } \\
\text { www.karger.com/cro }\end{array}$ \\
\hline
\end{tabular}

Ozeki et al.: Esophagobronchial Fistula in a Patient with Squamous Cell Carcinoma of the Lung: A Case Report

\section{References}

1 Chan KP, Eng P, Hsu AA, Huat GM, Chow M: Rigid bronchoscopy and stenting for esophageal cancer causing airway obstruction. Chest 2002;122:1069-1072.

-2 Martini N, Goodner JT, D’Angio GJ, Beattie EJ Jr: Tracheoesophageal fistula due to cancer. J Thorac Cardiovasc Surg 1970;59:319-324.

- 3 Herth FJ, Peter S, Baty F, Eberhardt R, Leuppi JD, Chhajed PN: Combined airway and oesophageal stenting in malignant airway-oesophageal fistulas: a prospective study. Eur Respir J 2010;36:13701374.

-4 Yamada S, Takai Y, Ogawa Y, Kakuto Y, Sakamoto K: Radiotherapy for malignant fistula to other tract. Cancer 1989;64:1026-1028.

$5 \quad$ Kvale PA, Simoff M, Prakash UB; American College of Chest Physicians: Lung cancer. Palliative care. Chest 2003;123(suppl):284S-311S.

-6 Segawa Y, Kiura K, Takigawa N, Kamei H, Harita S, Hiraki S, Watanabe Y, Sugimoto K, Shibayama T, Yonei T, Ueoka H, Takemoto M, Kanazawa S, Takata I, Nogami N, Hotta K, Hiraki A, Tabata M, Matsuo K, Tanimoto M: Phase III trial comparing docetaxel and cisplatin combination chemotherapy with mitomycin, vindesine, and cisplatin combination chemotherapy with concurrent thoracic radiotherapy in locally advanced non-small-cell lung cancer: OLCSG 0007. J Clin Oncol 2010;28:3299-3306.
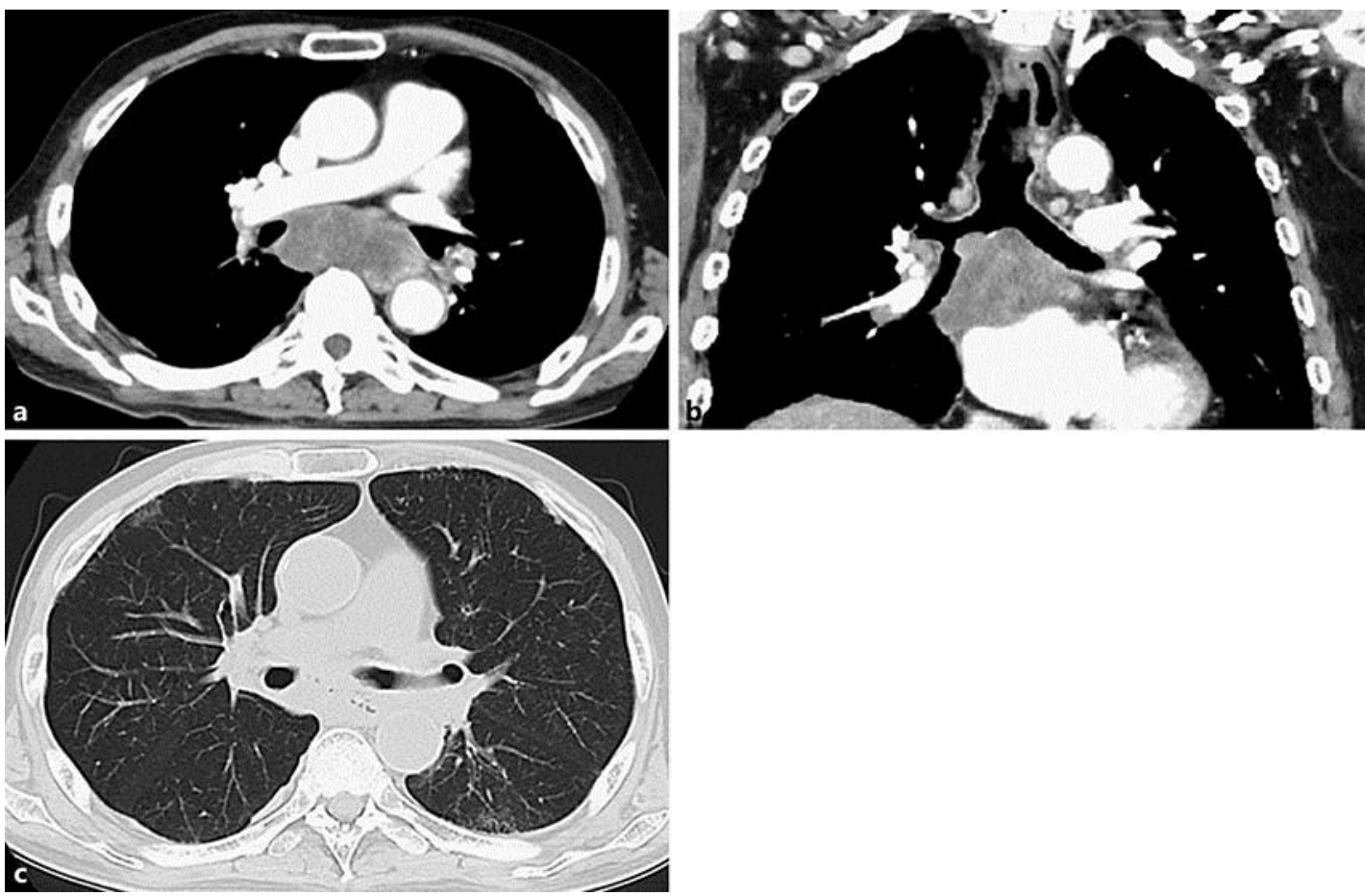

Fig. 1. Computed tomography (CT) of the chest at the initial presentation showing a mass grouped with mediastinal lymph nodes, which invaded the right main bronchus: axial view (a) and coronal view (b). c The CT of the chest on day 35 of treatment demonstrated punctate low-attenuation foci between the esophagus and bronchus. 


\section{Case Reports in Oncology}
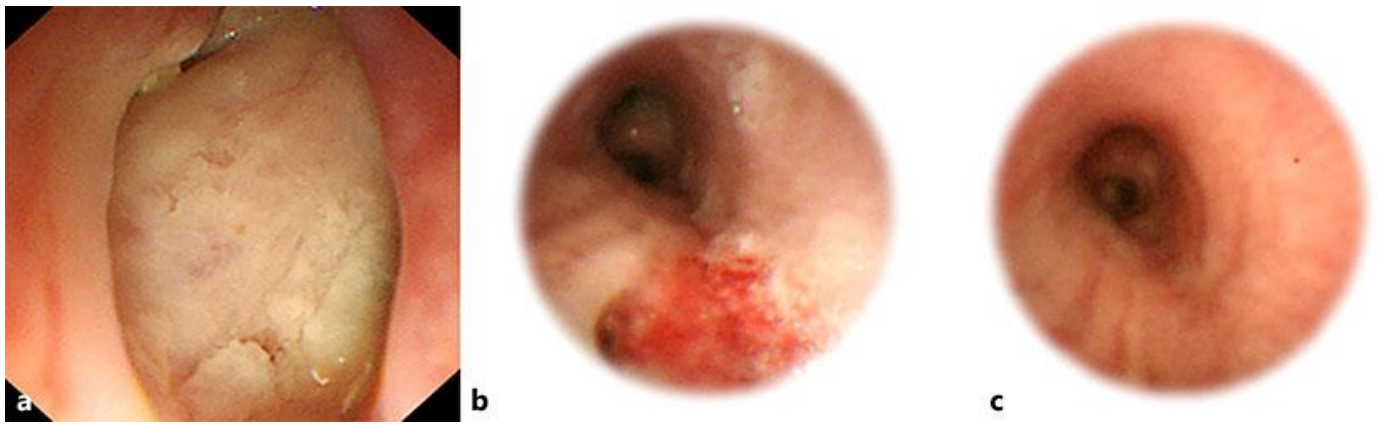

Fig. 2. Gastrointestinal endoscopy and bronchoscopy demonstrated a fistula in the middle intrathoracic esophagus (a) and the left main bronchus (b), respectively. After the suspension of chemoradiotherapy and abstaining from eating, the fistula was closed (c).
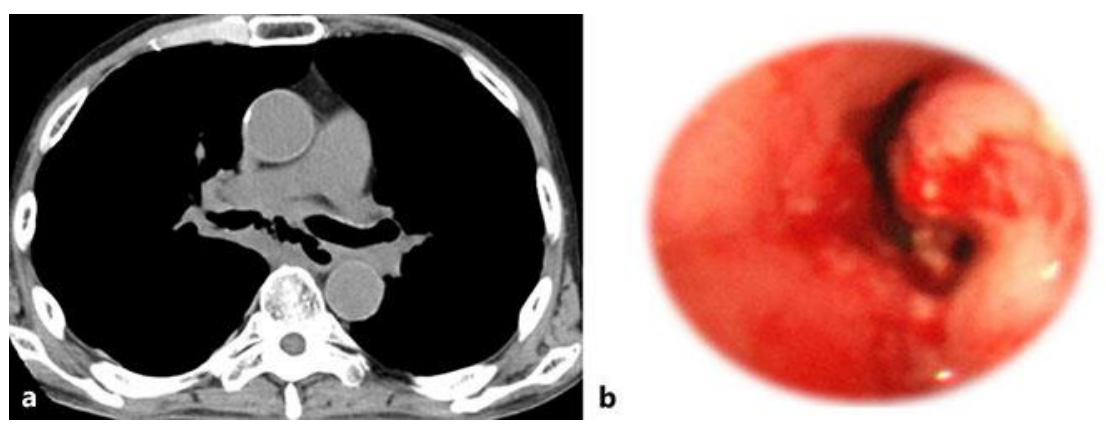

Fig. 3. a Computed tomography of the chest on day 108, showing a connection between the esophagus and the right main bronchus. b Bronchoscopy demonstrated a tumor with the fistula in the right main bronchus. 